\title{
Efeito da reidratação na germinação de sementes de açaí (Euterpe oleraceae Mart.)
}

The effect of the rehydration on seed germination of açaí (Euterpe oleraceae Mart.)

\author{
Patrícia Aparecida de Souza ${ }^{*}$, André Ferreira dos Santos $^{2}$, Douglas Santos Gonçalves ${ }^{3}$ \& Nelson \\ Venturin ${ }^{3}$ \\ ${ }^{1}$ Universidade Federal de São João del-Rei, São João del-Rei, MG, Brasil. *Autor para correspondência: patriciaapsouza@ufsj.edu.br. \\ ${ }^{2}$ Universidade Federal do Tocantins, Gurupi, TO, Brasil. \\ ${ }^{3}$ Universidade Federal de Lavras, Lavras, MG, Brasil.
}

Submissão: 31/07/2016 / Aceite: 09/05/2018

\begin{abstract}
RESUMO
O açaí (Euterpe oleraceae Mart.) é endêmico das matas ciliares da floresta pluvial da Amazônia e está frequentemente associado a ambientes degradados e de vegetação secundária. O objetivo, neste trabalho, foi avaliar o efeito da reidratação das sementes de açaí, visando acelerar e uniformizar a germinação. O lote de sementes foi coletado na região de Manaus, estado do Amazonas, Brasil. O esquema experimental utilizado foi o delineamento em blocos casualizados (DBC), com seis tratamentos (0, sem embebição (T1) e 3 (T2), 6 (T3), 9 (T4), 12 (T5) e 15 (T6) dias de reidratação por embebição em água), com sete repetições de 25 sementes. A semeadura foi realizada logo após o processo de reidratação. A avaliação da germinação ocorreu a cada 10 dias, com a contagem das sementes germinadas. As médias foram comparadas pelo teste de Scott-Knott, a 5\% de probabilidade. Na avaliação do percentual de germinação, observou-se diferença significativa entre a testemunha (T1) e os demais períodos de reidratação (T4>T6>T5>T2>T3). Os resultados mostraram que o processo de reidratação foi favorável à produção de mudas, pois proporcionou maior porcentagem de germinação de sementes de açaí $O$ pré-tratamento de reidratação acelerou a germinação das sementes e o melhor período de reidratação foi o de 9 dias, porque apresentou maior índice de velocidade de emergência de plântulas (IVE), além do menor tempo exigido para a condução do pré-tratamento.
\end{abstract}

PALAVRAS-CHAVE: palmeira, Arecaceae, produção de mudas.

\section{ABSTRACT}

The açaí (Euterpe oleraceae Mart.) is abundant in riparian forest of pluvial forest from the Amazonian region and is frequently associated with degraded environments of secondary vegetation. The objective of this work was to evaluate the effect of rehydration of açaí seeds, aiming to speed up and create uniform patterns for the seed germination. The experimental design used was random blocks with six treatments (rehydration by soaking the seeds in water for 0 (T1), 3 (T2), 6 (T3), 9 (T4), 12 (T5) or 15 (T6) days), with seven repetitions of 25 seeds each. The seeds were sown soon after the rehydration process. Germination was evaluated every 10 days by counting the germinated seeds. The averages were compared with the Scott-Knott test to the level of $5 \%$ probability. The results showed significant differences among the control (T1) and the others periods of rehydration (T4>T6>T5>T2>T3), which did not show significant differences among them. The results showed that the rehydration process favored seedlings production, as it provided a higher percentage of açaí seed germination. The pre-treatment of rehydration accelerated the germination of the seeds; and the best rehydration period was 9 days, because it presented a higher seedling emergence rate index (IVE), in addition to the shorter time required to conduct the pre-treatment. KEYWORDS: palm, Arecaceae, seedlings production.

\section{INTRODUÇÃO}

As palmeiras (Arecaceae) são plantas que se distribuem de maneira pantropical, ocorrendo em praticamente todas as formações vegetais (SOUZA \& LORENZI 2012). No Brasil, são descritas cerca de 270 espécies e 38 gêneros nativos (LEITMAN et al. 2014).

As palmeiras contribuem na alimentação, como matéria-prima para a construção de casas, para 
ornamentação e na produção de artesanatos, remédios e utensílios domésticos (SOARES et al. 2014). As populações ribeirinhas convivem com grande diversidade desses recursos naturais que são explorados por meio de diversas técnicas, com base no conhecimento obtido de seus antepassados ou, mesmo, com a experiência de campo (ALMEIDA \& JARDIM 2012). Dentre as espécies exploradas por essa população está a Euterpe oleraceae, conhecida popularmente como açaí.

Apresentando grande importância para as populações do baixo Amazonas e da região do estuário (PONTES 2013), o açaizeiro destaca-se pela aceitação do fruto e por suas inúmeras características nutricionais que, atualmente, se tornaram fonte de múltiplos produtos industrializados. Destaca-se, ainda, o seu valor como fonte de alimento e renda para comunidades rurais de uma extensa área da região Amazônica (SACRAMENTO et al. 2015).

No estado do Pará registrou-se, nos últimos anos, o crescente aumento da área plantada com essa cultura em terra firme e manejada nas várzeas. Em 2015, as áreas plantadas e manejadas de açaí no estado eram de 154.486 ha e produção média de 1.011 .685 toneladas (SAGRI 2016).

Visando diminuir a pressão extrativista da espécie e a exploração irracional e desenfreada dos recursos naturais na Amazônia, há a real necessidade de estudos para subsidiar a produção agrícola sustentável na região. Nesse sentido, o desenvolvimento de plantios que venham suprir a demanda pelo açaí e seus derivados é relevante para o desenvolvimento regional sustentável.

O sucesso na produção de mudas constitui uma das etapas essenciais na implantação de lavouras, fase que requer um pacote tecnológico bem desenvolvido, considerando as características ecológicas e silviculturais das espécies alvos.

Após a coleta, os frutos de açaí devem ser beneficiados e as sementes colocadas para germinar, para que se obtenha alto percentual de germinação (LORENZI 2002). Quando a semeadura imediata não é possível, o armazenamento das sementes apresenta-se como um obstáculo, pois, 15 dias após a coleta, os frutos começam a perder a viabilidade, requerendo um processo de reidratação antes do plantio.

O processo de reidratação das sementes pela pré-embebição em água tem a função de prepará-las para a semeadura, fazendo com que se iniciem os processos bioquímicos de reativação da atividade metabólica (LIMA et al. 2013). NATH et al. (1991) relataram que os tratamentos de pré-semeadura possibilitam a garantia de alto percentual de germinação, uniformizando a emergência de plântulas e aumentando a resistência aos efeitos adversos do ambiente.

Neste contexto, o presente trabalho foi realizado com o objetivo de avaliar o efeito da reidratação das sementes de açaí (Euterpe oleraceae) na germinação, visando à uniformização na emergência de plântulas.

\section{MATERIAL E MÉTODOS}

O trabalho foi desenvolvido no Laboratório de Sementes e no Viveiro Florestal da Universidade Federal do Amazonas (UFAM), Manaus, AM, localizado nas coordenadas geográficas correspondentes a $03^{\circ} 04^{\prime} 34^{\prime \prime}$ latitude S e $59^{\circ} 57^{\prime}$ ' 50" longitude W.

O lote de sementes de Euterpe oleraceae foi coletado na região de Manaus. As sementes foram obtidas submetendo-se os frutos maduros recém-colhidos ao despolpamento manual e à lavagem do material em água corrente, para a eliminação de resíduos do epicarpo e do mesocarpo. Em seguida, foram realizados a seleção manual e o descarte das sementes mal formadas. Determinou-se o teor de água das sementes pelo método da estufa, a $105^{\circ} \mathrm{C}$, por 24 horas, conforme estabelecido pelas Regras para Análise de Sementes (RAS) (BRASIL 2009).

As sementes obtidas foram misturadas e imersas em água (com a substituição diária), monitorandose diariamente o aumento de massa em quatro amostras de dez sementes. A partir da umidade inicial, foi possível mensurar a umidade das sementes ao longo do período de reidratação.

De acordo com o tempo em que a semente permaneceu em hidratação (FERREIRA \& GENTIL 2002), a semeadura foi realizada em 0 dias (T1 - testemunha), 3 dias (T2), 6 dias (T3), 9 dias (T4), 12 dias (T5) e 15 dias (T6). As sementes foram colocadas para germinar em condições de casa de vegetação $(60 \%$ de luminosidade), em bandejas de $80 \times 40 \times 20 \mathrm{~cm}$, tendo como substrato areia lavada e uma fina camada de vermiculita, com a finalidade de manter a umidade do substrato.

As irrigações foram diárias (BRASIL 2009). A avaliação da germinação foi realizada a cada dez dias, até atingir 90 dias, com a contagem das sementes que apresentaram o intumescimento do embrião, o que ocorreu após a emergência. As sementes mortas e dormentes foram contadas no final do período experimental.

As avaliações foram realizadas até o momento da última contagem. Ao final do teste, o percentual de germinação e o índice de velocidade de germinação (IVG) foram calculados de acordo com MAGUIRE 
(1962). A determinação da umidade e do percentual de sementes dormentes foi realizada conforme as recomendações da RAS (BRASIL 2009).

$O$ esquema experimental utilizado foi o delineamento em blocos casualizados (DBC) com seis tratamentos (0 (T1), 3 (T2), 6 (T3), 9 (T4), 12 (T5) e 15 (T6) dias de reidratação), com sete repetições de 25 sementes. Para a análise de variância, os dados de percentual de germinação foram transformados em arcsen $\sqrt{ } \mathrm{x} / 100$ e os de sementes dormentes e mortas em $\sqrt{ } \mathrm{x}+0,5$. As médias foram comparadas pelo teste de SCOTT \& KNOTT (1974), a 5\% de probabilidade, por meio do software ASSISTAT 7.7 beta (SILVA 2016).

\section{RESULTADOS E DISCUSSÃO}

O percentual de germinação de Euterpe oleraceae foi superior nos tratamentos em que as sementes foram reidratadas (T2, T3, T4, T5 e T6), se comparados com a testemunha (T1), que apresentou $2 \%$ de viabilidade (Tabela 1). A umidade das sementes da testemunha (T1), por não estar hidratada, foi muito inferior à dos demais tratamentos, 15,02\%, podendo estar associada à perda de viabilidade. Resultado semelhante foi relatado por OLIVEIRA et al. (2002), em cujo trabalho sementes de açaí que apresentavam grau de umidade em torno de $14 \%$ perderam completamente a capacidade de germinar.

O baixo percentual de germinação das sementes de açaí ocorreu porque a maioria das sementes de palmeiras são consideradas recalcitrantes, ou seja, não toleram o processo de secagem em determinado teor de água e necessitam de elevada umidade para germinação, apresentando grau de umidade crítico na faixa de 34,2 a 37,4\% (ARAÚJO et al. 1994, COSTA 2015). Na condução do experimento, as sementes ficaram armazenadas por um período de 15 dias, resultando em menor teor de água. De acordo com MARCOS FILHO (2005), quando as sementes de açaí atingem o ponto de maturação fisiológica na planta mãe, o teor de umidade é alto, oscilando entre $50 \%$ e $70 \%$. À medida que essa umidade vai diminuindo, as reações metabólicas no interior da semente também vão diminuindo e ela, consequentemente, começa a perder a viabilidade. O processo de reidratação é importante, para aumentar a porcentagem de germinação.

A principal dificuldade para o cultivo de mudas de açaizeiro em grande escala é a germinação que, normalmente, ocorre de forma lenta e desuniforme, sendo quase sempre menor que $60 \%$ e com elevado tempo de permanência das sementes no solo (GUEDES et al. 2014).

As sementes não reidratadas (T1) apresentaram também baixa velocidade de emergência de plântulas (IVE=0,04\%), quando comparadas com as dos demais tratamentos (Tabela 1). Este fato demonstra a importância da água, ou seja, da reidratação na germinação de sementes, principalmente das recalcitrantes, pois a viabilidade e a germinação das sementes recalcitrantes dependem diretamente do grau de umidade (ARRUDA et al. 2016). A água é o principal fator para o início da germinação e exerce influência determinante neste processo (CARVALHO \& NAKAGAWA 1988).

O processo de germinação inicia-se pela absorção de água por embebição. O processo de absorção de água resulta na reidratação dos tecidos das sementes, consequentemente intensificando a respiração e outras atividades metabólicas envolvidas no fornecimento de energia e nutrientes necessários para a retomada do crescimento do eixo embrionário (CARVALHO \& NAKAGAWA 1988). Para isso, é necessário que a semente alcance um nível adequado de hidratação, de forma a viabilizar a reativação dos processos metabólicos (BORGES \& RENA 1993).

Em sementes de açaí que apresentavam alto teor de umidade e colocadas para germinar, o processo ocorreu mais rapidamente, tendo o percentual de germinação sido maior, estatisticamente, nos tratamentos em que as sementes foram reidratadas, na comparação com o tratamento testemunha (T1), sem reidratação (Tabela 1 ).

A reidratação possibilitou um aumentou no índice de velocidade de emergência de plântulas de açaí IVE (\%). O tratamento T4 (9 dias de embebição em água) apresentou o maior IVE (\%), diferindo estatisticamente dos demais tratamentos (Tabela 1). Em sementes de Astrocaryum aculeatum, após nove dias de embebição em água, o percentual de germinação foi maior (FERREIRA \& GENTIL 2006, FERREIRA et al. 2010).

A reidratação pela embebição em água é um processo simples e prático, e tem sido uma das tecnologias mais testadas atualmente, em espécies arbóreas e arbustivas, exóticas e nativas, a exemplo da Copernicia prunifera (SILVA et al. 2009), Astrocaryum aculeatum (FERREIRA et al. 2010), Apeiba tibourbou (GUEDES et al. 2011), Morinda citrifolia (OLIVEIRA et al. 2011), Jatropha curcas L. (BRAGA et al. 2012), Moringa oleifera (RABBANI et al. 2013) e Copernicia hospital (PEREIRA et al. 2014).

Os maiores valores de umidade (\%) foram obtidos nos tratamentos T4 $(37,93 \%)$, T5 $(37,79 \%)$ e T6 
(37,26\%) (Tabela 1). Observou-se que os tratamentos T5 e T6 (12 e 15 dias de embebição em água, respectivamente) apresentaram tendência de diminuição dos teores de umidade, provocando, consequentemente a diminuição do percentual de germinação (Tabela 1). OLIVEIRA et al. (2002) relataram que quanto maior o grau de umidade das sementes, maior o percentual de germinação, e que sementes oriundas de frutos recém-colhidos e imediatamente processados apresentam alto percentual de germinação, acima de $90 \%$.

Tabela 1. Médias dos tratamentos testados no experimento, umidade (U), germinação (G), índice de velocidade de emergência de plântulas (IVE), e sementes apodrecidas (SA), determinados em sementes de Euterpe oleraceae Mart.

Table 1. Averages of treatments tested in the experiment, moisture (U), germination (G), seedling emergence velocity (IVE), and rotted seeds (SA), determined in Euterpe oleraceae Mart.

\begin{tabular}{lllll}
\hline Tratamentos & $\mathrm{U}(\%)$ & $\mathrm{G}(\%)$ & $\mathrm{IVE}$ & $\mathrm{SA}(\%)$ \\
\hline 1 (sem reidratação) & $15,02 \mathrm{c}$ & $2,00 \mathrm{~b}$ & $0,04 \mathrm{~d}$ & $93,14 \mathrm{a}$ \\
2 (3 dias de reidratação) & $36,51 \mathrm{~b}$ & $61,71 \mathrm{a}$ & $1,57 \mathrm{c}$ & $28,00 \mathrm{~b}$ \\
3 (6 dias de reidratação) & $36,61 \mathrm{~b}$ & $62,50 \mathrm{a}$ & $1,44 \mathrm{c}$ & $34,85 \mathrm{~b}$ \\
4 (9 dias de reidratação) & $37,93 \mathrm{a}$ & $80,00 \mathrm{a}$ & $2,16 \mathrm{a}$ & $19,42 \mathrm{~b}$ \\
5 (12 dias de reidratação) & $37,79 \mathrm{a}$ & $68,00 \mathrm{a}$ & $1,64 \mathrm{c}$ & $28,57 \mathrm{~b}$ \\
6 (15 dias de reidratação) & $37,26 \mathrm{a}$ & $70,28 \mathrm{a}$ & $1,86 \mathrm{~b}$ & $28,00 \mathrm{~b}$ \\
\hline CV $(\%)$ & 1,58 & 62,35 & 16,96 & 24,42 \\
\hline
\end{tabular}

Médias seguidas pela mesma letra não diferem entre si, pelo teste de Scott e Knott, a 5\% de probabilidade.

GUEDES et al. (2011), trabalhando com sementes de Apeiba tibourbou, demonstraram que a embebição em água por 12 horas proporcionou germinação de 70\%, entretanto, quando o tempo de permanência em água aumentou para 24 horas, registrou-se redução significativa no percentual de germinação (51\%). Para os autores, a embebição, possivelmente, foi o fator limitante para a germinação nestas condições, devido aos danos ocorridos durante a embebição por períodos prolongados (24 horas), os quais permitiram que os tecidos se tornassem mais tenros e, portanto, mais suscetíveis ao ataque de fungos.

De acordo com estudos realizados por NASCIMENTO et al. (2007), a desidratação crescente $(37,4 \%$; $30,3 \% ; 26,1 \% ; 21,0 \% ; 15 \%$ e $11,9 \%$ ) afetou o vigor das sementes de açaí, resultando no aumento do tempo médio de germinação, na redução da velocidade de emergência das plântulas, no comprimento e na matéria seca.

Sementes de E. oleraceae apresentaram elevado percentual de germinação (80\%) para a umidade de $37,93 \%$ e baixo percentual de germinação em $15,02 \%$ de umidade (Tabela 1). NASCIMENTO \& SILVA (2005) avaliaram o efeito da desidratação nas sementes desta espécie e observaram que, até o nível de $39 \%$, ela não produziu efeitos fisiológicos imediatos sobre as sementes. A desidratação a partir de $33 \%$ de água provocou progressiva redução da germinação e, ao atingir $15 \%$ de água na semente, a capacidade germinativa foi anulada.

A pré-embebição de propágulos de Copernicia hospita por um período de cinco dias uniformizou o percentual de emergência, tendo sido reportados valores na faixa de 75\% a 78\% (PEREIRA et al. 2014) e, para Copernicia prunifera, sob as mesmas condições, eles oscilaram entre $82 \%$ a $91 \%$ (SILVA et al. 2009).

BRAGA et al. (2012) demonstraram que a hidratação promoveu o aumento do comprimento, da massa seca de plântulas e favoreceu a emergência de plântulas de Jatropha curcas. RABBANI et al. (2013) relatam que a imersão das sementes de Moringa oleifera em água por 24 horas resultou em maior viabilidade e vigor.

Para a produção de mudas de Copernicia prunifera, SILVA et al. (2009) recomendam a utilização de sementes pré-embebidas em água durante o período de 12 dias, até a protrusão do pecíolo cotiledonar, e que a semeadura deve ocorrer a $21 \mathrm{~mm}$ de profundidade.

Os tratamentos que apresentaram maior teor de umidade ( $T 4>\mathrm{T} 6>\mathrm{T} 5>\mathrm{T} 2>\mathrm{T} 3$ ) resultaram nos maiores índices de velocidade de emergência (IVE), ficando menos tempo nas sementeiras, evitando, assim, a perda, principalmente pelo apodrecimento (Tabela 1).

Por meio da análise dos resultados obtidos, a reidratação proporcionou efeitos positivos, sobretudo pelo período de 9 dias (T4), que resultou em maior índice de velocidade de emergência de plântulas (IVE) e menor tempo exigido para a condução do pré-tratamento, quando comparado com os tratamentos T5 e T6 (Tabela 1). Esta constatação é importante, uma vez que, para MARTINS et al. (1999), a germinação mais 
lenta faz com que as sementes e as plântulas fiquem mais vulneráveis e sujeitas a condições adversas do meio por mais tempo, acarretando na deterioração dos propágulos.

Para a espécie Edulis espiritosantensis, a desidratação crescente intensificou o processo de degradação das sementes, o que foi observado na análise da velocidade de emergência de plântulas (IVG), da porcentagem de germinação, do comprimento das plântulas e do aumento do número de sementes mortas (MARTINS et al. 1999).

Devido à simplicidade e à facilidade, no que concerne à utilização do processo de hidratação por meio da embebição em água, recomenda-se a condução de estudos que levem em conta espécies florestais de interesse econômico, para que a metodologia possa ser divulgada e utilizada para a produção de mudas, principalmente pelos pequenos produtores.

\section{CONCLUSÃO}

O processo de reidratação foi favorável à produção de mudas, pois proporcionou maior porcentagem de germinação de sementes de Euterpe oleracae (açaizeiro).

O pré-tratamento de reidratação acelera a germinação das sementes e o melhor período de reidratação é o de 9 dias, o qual apresentou maior índice de velocidade de emergência de plântulas (IVE), além do menor tempo exigido para a condução do pré-tratamento.

\section{REFERÊNCIAS}

ALMEIDA AF \& JARDIM MAG. 2012. Utilização das espécies arbóreas da floresta de várzea da Ilha de Sororoca, Ananindeua, Pará, Brasil por moradores locais. Revista Brasileira de Ciências Ambientais 23: 48-54.

ARAÚJO EF et al. 1994. Avaliação da qualidade de sementes de açaí armazenadas em diferentes embalagens e ambientes. Revista Brasileira de Sementes 16: 76-79.

ARRUDA NV et al. 2016. Superação de dormência de sementes de araçá-boi, utilizando giberelina. III Congresso de Ensino, Pesquisa e Extensão da UEG. Anais...Pirenópolis: UEG. 4p.

BORGES EEL \& RENA AB. 1993. Germinação de sementes. In: AGUIAR IB et al. Sementes florestais tropicais. Brasília: ABRATES. p. 83-135.

BRAGA NS et al. 2012. Hidratação controlada de sementes de pinhão manso. Revista de Ciência Agronômica 43: 589597.

BRASIL. 2009. Ministério da Agricultura, Pecuária e Abastecimento. Regras para Análise de Sementes. Brasília: MAPA/ACS. 399p.

CARVALHO NM \& NAKAGAWA J. 1988. Sementes: ciência, tecnologia e produção. 3.ed. Campinas: Fundação Cargill. $424 p$.

COSTA CRX. 2015. Temperatura, luz e tolerância à dessecação na germinação de sementes de açaí-do-amazonas. Dissertação (Mestrado em Agronomia). Jaboticabal: USP. 38p.

FERREIRA SAN et al. 2010. Emergência de plântulas de tucumã (Astrocaryum aculeatum) em função do pré-tratamento das sementes e da condição de semeadura. Revista Brasileira Fruticultura 32: 1189-1195.

FERREIRA SAN \& GENTIL DFO. 2002. Beneficiamento, pré-tratamento e germinação de sementes de tucumã (Astrocaryum aculeatum Meyer - Arecaceae). In: 17 Congresso Brasileiro de Fruticultura. Anais... Belém: EMBRAPA. (CD-Rom).

FERREIRA SAN \& GENTIL DFO. 2006. Extração, embebição e germinação de sementes de tucumã (Astrocaryum aculeatum). Acta Amazonica 36: 141-146.

GUEDES C et al. 2014. Testes de quebra de dormência em sementes de açaí. Anais Programa Ciência na Escola. Acre: Escola Estadual Danilo Correa. p. 14-16.

GUEDES RS et al. 2011. Tratamentos pré-germinativos e temperaturas para a germinação de sementes de Apeiba tibourbou Aubl. Revista Brasileira de Sementes 33: 131-140.

LEITMAN P et al. 2014. Arecaceae. In: Lista de Espécies da Flora do Brasil. Jardim Botânico do Rio de Janeiro. Disponível em < http://floradobrasil.jbrj.gov.br/reflora >. Acesso em: 28 mar. 2016.

LIMA CB de. et al. 2013. Tratamentos de pré-embebição e qualidade fisiológica de sementes de abóbora. In: 8 Congresso Brasileiro de Agroecologia. Resumos... Porto Alegre: Cadernos de Agroecologia. 5p.

LORENZI H. 2002. Árvores brasileiras: manual de identificação e cultivo de plantas arbóreas do Brasil. 4.ed. Nova Odessa: Instituto Plantarum. 368p.

MAGUIRE JD. 1962. Speed of germination: aid in selection and evaluation for seedling emergence and vigor. Crop Science 2: 176-177.

MARCOS FILHO J. 2005. Sementes recalcitrantes. In: MARCOS FILHO J. Fisiologia de sementes de plantas cultivadas. Piracicaba: FEALQ. p. 353-381.

MARTINS CC et al. 1999. Teores crítico e letal de água para sementes de açaizeiro (Euterpe oleraceae Mart.). Revista Brasileira de Sementes 21: 125-132.

NASCIMENTO WMO et al. 2007. Consequências fisiológicas da dessecação em sementes de açaí (Euterpe oleraceae Mart.). Revista Brasileira de Sementes 29: 38-43. 
NASCIMENTO WMO \& SILVA WR. 2005. Comportamento fisiológico de semente de açaí (Euterpe oleraceae Mart.) submetidas à desidratação. Revista Brasileira de Fruticultura 27: 349-351.

NATH S. et al. 1991. Hydratation-dehydration treatments to protect or repair stored 'Karamu' weat seeds. Crop Science 31: 822-826.

OLIVEIRA KP et al. 2011. Desponte e embebição em sementes de noni (Morinda citrifolia L.). Revista Brasileira de Plantas Medicinais 13: 513-517.

OLIVEIRA MSP. et al. 2002. Cultivo do Açaizeiro para Produção de Frutos. Belém: Embrapa Amazônia Oriental. 18p. (Circular Técnica, 26).

PEREIRA DS et al. 2014. Influência da maturação dos frutos na emergência e crescimento inicial de Copernicia hospita Mart. - Arecaceae. Revista Ciência Agronômica 45: 214-220.

PONTES RX. 2013. Assahy-yukicé, iassaí, oyasaí, quasey, açãy, jussara, manaca, açaí, acay-berry: rizoma. Tese (Doutorado em Ciências Sociais). Belém: UFPA. 163p.

RABBANI ARC et al. 2013. Pré - embebição em sementes de moringa. Scientia Plena 9: 1-8.

SAGRI. 2016. Secretária de Estado da Agricultura. Anuário Brasileiro da Fruticultura 2016. Santa Cruz do Sul: Editora Gazeta Santa Cruz. 92p. Disponível em: <http://www.grupogaz.com.br/tratadas/eo_edicao/4/2016/04/20160414_0d40 a2e2a/pdf/5149_2016fruticultura.pdf>. Acesso em: 18 jun. 2016.

SACRAMENTO JMC. et al. 2015. Açaí no Norte e juçara no Sul: A necessidade do estudo de cadeias de produtos. In: 9 Congresso Brasileiro de Agroecologia. Resumos... Belém: Cadernos de Agroecologia. 5p.

SCOTT AJ \& KNOTT M. 1974. A cluster analysis method for grouping means in the analysis of variance. Biometrics 30 : 507-512.

SILVA F de AS. 2016. ASSISTAT: Versão 7.7 beta. DEAG-CTRN-UFCG - Atualizado em 01 de março de 2016. Disponível em: <http://www.assistat.com/>. Acesso em: 17 jun. 2016.

SILVA FDB. et al. 2009. Pré-embebição e profundidade de semeadura na emergência de Copernicia prunifera (Miller) H. E Moore. Revista Ciência Agronômica 40: 272-278.

SOARES KP et al. 2014. Palmeiras (Arecaceae) no Rio Grande do Sul, Brasil. Rodriguésia 65: 113-139.

SOUZA VC \& LORENZI H. 2012. Botânica Sistemática: guia ilustrado para identificação das famílias de Fanerógamas nativas e exóticas no Brasil, baseado em APG III. 3.ed. Nova Odessa: Instituto Plantarum. 768p. 